\title{
Uma abordagem centrada no aluno para ensinar Química: estimulando a participação ativa e autônoma dos alunos
}

\section{A student-centered approach to teach Chemistry: stimulating active and autonomous student participation}

\author{
Camila Aparecida Tolentino Cicuto ${ }^{1}$ \\ https://orcid.org/0000-0002-9817-7933 \\ Ana Carolina Gomes Miranda ${ }^{1}$ \\ https:// orcid.org/0000-0003-1090-054X \\ Sinara da Silva Chagas ${ }^{1}$ \\ https://orcid.org/0000-0002-4822-4885
}

\begin{abstract}
Resumo: Neste artigo, investigou-se um componente de Química em que o ensino é centrado no aluno. Assim, as aulas são organizadas por meio de períodos de estudo (PE) e grupos de discussão (GD), além da utilização de mapas conceituais e Histórias em Quadrinhos como recursos didáticos. Teve-se por objetivo verificar a percepção dos alunos $(n=26)$ sobre o ambiente de aprendizagem proporcionado nesse componente. Como instrumento de coleta de dados, utilizou-se um questionário com seis perguntas abertas acompanhadas de uma escala numérica de 10 níveis (1- pouco; 10- muito). Análise dos dados combinou as abordagens quantitativas e qualitativas. Os resultados indicaram que os alunos avaliaram positivamente o componente de Química. Esse resultado é de grande relevância, pois ratifica a importância de se promover ambientes de aprendizagem que permitem a participação ativa e autônoma dos acadêmicos, em prol da qualidade do Ensino Superior.
\end{abstract}

Palavras-chave: Formação de professores. Ensino de química. Aprendizagem ativa. Ensino centrado no aluno.

\begin{abstract}
For the present article we have investigated a student-centered Chemistry course. In this context, classes are organized through periods of study (PS) and discussion groups (DG), in addition to the use of concept maps and Comics as teaching resources. The objective of this study was to assess the students' $(\mathrm{n}=26)$ perception about the learning environment provided in this course. A questionnaire, with six open questions and a numerical scale of 1-10 (1- little; 10- a lot), was used as the instrument to collect data. Data analysis employed a combination of quantitative and qualitative approaches. Overall, the students provided positive evaluations for the Chemistry course. This result is of great relevance, since it ratifies the importance of developing learning environments that stimulate active and autonomous student participation, thus promoting quality learning in Higher Education.
\end{abstract}

Keywords: Teacher education. Chemistry teaching. Active learning. Student-centered teaching.

\footnotetext{
${ }^{1}$ Universidade Federal do Pampa (Unipampa), Dom Pedrito, RS, Brasil. E-mail: camilacicuto@unipampa.edu.br
} 


\section{Introdução}

A urgência pela efetivação de práticas pedagógicas que oportunizem um Ensino Superior de qualidade é evidenciada em vários trabalhos na literatura (ATAÍDE; LIMA; ALVES, 2006; BEHRENS, 2011; COHEN; ROBINSON, 2018; ESTEVES, 2008; KEMBER, 2009). Esses trabalhos indicam o potencial das atividades colaborativas como estratégia para modificar a concepção de ensino e aprendizagem baseada na transmissão-recepção. Isso implica alterar não só a configuração da sala de aula, mas também o papel do professor e dos alunos. Em relação à sala de aula, as cadeiras enfileiradas são substituídas pela disposição em círculo. Nessa dinâmica, os professores proporcionam desafios para que os estudantes, em grupos, estudem e proponham resoluções aos problemas apresentados. Assim, o professor deixa seu papel de detentor do conhecimento e assume a posição de mediador do processo de aprendizagem. É a partir desses pressupostos que uma prática educativa crítica e reflexiva pode emergir. Contudo, apesar dos inúmeros trabalhos nos últimos anos em torno dessa temática, a prática docente ainda é marcada pelo modelo de transmissão-recepção, permanecendo presa ao pensamento neutro, linear, cartesiano e positivista.

Esse ensino clássico está arraigado ao contexto educacional, sendo aplicado por professores sem qualquer reflexão sobre a sua prática. Nesse sentido, Moreira (2011, p. 1, grifo do autor) argumenta que este modelo é "consagrado e aceito sem questionamento por professores, alunos e pais e pela sociedade em geral, é aquele em que o professor ensina, básica e fundamentalmente falando, dizendo aos estudantes o que se supõe que devam saber [...]". Assim, mudar essa concepção exige um grande esforço coletivo de professores e da comunidade científica para efetivar e divulgar práticas que possibilitem a participação ativa e autônoma dos alunos na construção do conhecimento. Mas por que a dinâmica da sala de aula não muda?

A formação dos professores universitários tem grande influência na estabilidade desse modelo de ensino. É comum ouvir esses profissionais dizerem que sempre fizeram assim e não mudarão sua prática. Isso porque, para ingressar nas Universidades públicas do país, exigem-se os títulos de mestrado e doutorado, mesmo que não tenham qualquer formação e experiência pedagógica. No caso das instituições privadas, na maioria delas, esse cenário se agrava, pois, se buscam professores com menores salários e ainda salas de aula com elevado número de alunos, tornando o modelo de transmissão-recepção quase inevitável. Assim, os docentes universitários acabam reproduzindo o modelo que aprenderam ao longo de suas vidas escolares e universitárias. É como se, para ser professor, bastasse o domínio do conteúdo, apesar dos vários trabalhos indicando a importância do conhecimento pedagógico do conteúdo (Pedagogical Content Knowledge, PCK) na atividade docente (MONTENEGRO; FERNANDEZ, 2015; ROLLNICK et al., 2008). Essa situação é ainda mais complexa nos cursos de Licenciatura, uma vez que envolve a formação de professores para atuarem na Educação Básica. Igualmente, o modelo de transmissão-recepção também é replicado nas escolas de Ensino Médio e Fundamental, tornado a tarefa de mudar a configuração da sala de aula uma tarefa ainda mais árdua. Além da formação, a valorização profissional dos docentes das Universidades Públicas depende, quase exclusivamente, de suas publicações. Ou seja, a qualidade de suas aulas tem pouco ou nenhum impacto para eles (MOREIRA, 2017). Assim, oportunizar momentos de formação pedagógica para professores universitários, e valorizar essa atribuição dos docentes, tem um papel fundamental para mudar este cenário (ESTEVES, 2008). 
Uma abordagem centrada no aluno para ensinar Química: ...

Justificados alguns dos fatores que contribuem para uma prática educativa dos séculos passados, serão apresentados a seguir diferentes alternativas para alterar a dinâmica da sala de aula tradicional.

\section{O ensino centrado no aluno e as diferentes estratégias ativas}

Como alternativa ao modelo de transmissão-recepção ou centrado no professor, a literatura apresenta o ensino centrado no aluno. Neste modelo de ensino, os estudantes são estimulados a participar ativamente da construção do conhecimento através de estímulos à sua autonomia. Contudo, este é um processo e, no início, o aluno não tem tal consciência. Por isso, o professor tem papel fundamental para estimular essas experiências (HARKEMA; SCHOUT, 2008).

Há diferentes estratégias para a efetivação do ensino centrado no aluno, tais como Aprendizagem Baseada em Problemas (ALLEN; DONHAM; BERNHARDT, 2011), Aprendizagem Baseada em Equipes (McMAHON, 2010; MICHAELSEN; SWEET, 2011), Instrução por Pares (MAZUR, 1999), Período de Estudos (PE) e Grupo de Discussão (GD) (ÁVILA JR.; TORRES, 2010; CICUTO; TORRES, 2016, 2017a, 2017b) e outros, além de uma série de recursos didáticos que oportunizam a colaboração entre os alunos. Neste artigo, optou-se pelas estratégias PE e GD e como recursos didáticos foram utilizados os mapas conceituais e as Histórias em Quadrinhos (HQs).

$\mathrm{O}$ PE e o GD são estratégias ativas utilizadas pelo professor e pesquisador Bayardo Baptista Torres há cerca de 30 anos. Nos $\mathrm{PE}$, os alunos estudam em pequenos grupos com a supervisão do professor. O docente não fornece respostas prontas aos estudantes e estimula que eles cheguem às suas próprias conclusões. Assim, eles precisam melhorar seus argumentos até que o professor considere que atingiram o objetivo proposto. Nessa perspectiva, o professor monitora e estimula os alunos a colaborarem para a resolução das atividades ao longo do curso (ÁVILA JR.; TORRES, 2010). A aprendizagem em pequenos grupos não acontece por acaso. Essa dinâmica precisa ser planejada para ser bem-sucedida, assim como qualquer outra atividade de ensino. A aparente falta de estrutura gerada pela natureza informal, solta ou aberta, pode gerar a sensação de que o planejamento pode ser dispensado. Contudo, colocar os alunos em grupo não significa que eles irão colaborar (GRIFFITHS, 2003).

Após estudarem nos PE, inicia-se o GD. Alunos e professores, reunidos em um único grupo, discutem as atividades realizadas na etapa anterior, com o objetivo de externalizar as dúvidas e/ou concepções alternativas que ainda não foram esclarecidas. O GD permite também a análise dos alunos de suas próprias soluções, em vez de respostas prontas. Para isso, o professor estimula a avaliação crítica e a capacidade de argumentar dos alunos ao apresentarem suas explicações. Nesse sentido, o docente não pode ficar preso a uma definição única idêntica do material de estudo, ou seja, os argumentos dos alunos precisam ser considerados para a construção do conhecimento (ÁVILA JR.; TORRES, 2010).

Diante do exposto, a problemática que norteou a presente pesquisa foi: Qual a percepção dos licenciandos quando estudam em um ambiente de aprendizagem centrado no aluno? 


\section{Contexto da pesquisa}

A coleta de dados da presente pesquisa ocorreu no âmbito de um componente de Química de um curso de Licenciatura em Educação do Campo. O referido curso é desenvolvido em regime de alternância. Essa dinâmica acontece por meio de dois tempos complementares: o Tempo Universidade (TU) e o Tempo Comunidade (TC). O TU prevê as atividades específicas de cada componente curricular, enquanto o TC está atrelado ao desenvolvimento de Projetos Interdisciplinares nas comunidades do campo.

As aulas do TU do componente de Química investigado na presente pesquisa (com 30 horas aula), oferecido na graduação do referido curso, têm como ementa os aspectos teóricos, metodológicos e práticos dos conceitos de ligações químicas, funções químicas, estequiometria, bem como da energia envolvida nas transformações químicas. Como sugerido anteriormente, nas aulas desse componente, foram utilizados períodos de estudo (PE) e grupo de discussão (GD) com o objetivo de oportunizar a participação ativa e autônoma dos alunos na construção do conhecimento. No PE (grupos com aproximadamente cinco integrantes), os estudantes receberam um roteiro com questões para orientar as leituras e proporcionar a interação entre eles com a mediação do professor. Além disso, foram orientados a estudarem o material proposto e a colaborarem com o grupo quando tivessem dúvidas. Como recurso didático, optou-se pelas HQs complementadas pelo livro-texto. Além disso, os estudantes elaboravam mapas conceituais (coletivos e individuais) para fomentar as discussões.

Depois de estudarem e responderem às questões do roteiro, eles eram reunidos em um único grupo ( $\mathrm{n}=26$ ) para o GD. Nesta etapa, os acadêmicos discutiam e comentavam suas compreensões sobre o material proposto. Assim, as dinâmicas do PE e GD foram repetidas para cada um dos conteúdos da ementa.

\section{Objetivo}

Teve-se por objetivo investigar a opinião dos alunos sobre o ambiente de aprendizagem proporcionado no componente de Química de um curso de Licenciatura. Seguem as questões que nortearam a coleta e análise de dados.

Qual a percepção dos alunos quanto:

a) à organização do componente?

b) ao nível de dificuldade do componente?

c) aos conteúdos abordados no componente?

d) à aprendizagem dos conceitos científicos?

e) ao método de ensino do componente?

f) aos recursos didáticos utilizados nas aulas (histórias em quadrinhos, mapas concei tuais) e estratégias (grupos de estudo/discussão)? 


\section{Metodologia}

\section{Coleta dos dados}

A coleta dos dados envolveu a aplicação de um questionário com seis perguntas abertas acompanhadas de uma escala numérica de 10 níveis $(1-10$, sendo 1 = pouco e 10 muito) para avaliar a opinião dos alunos $(\mathrm{n}=26)$ sobre o ambiente de aprendizagem proporcionado no componente de Química. Esses itens contemplam organização do componente, nível de dificuldade, conteúdos, aprendizagem, método de ensino e os recursos didáticos (HQs, mapas conceituais) e estratégias (grupos de estudo/discussão).

\section{Análise dos dados}

Diante da natureza subjetiva que caracteriza o contexto da sala de aula, optou-se por um estudo misto (mixed methods), correspondendo à integração de métodos quantitativos e qualitativos (JOHNSON; ONWUEGBUZIE, 2004). A estatística descritiva foi utilizada para obter uma apreciação geral dos dados quantitativos indicados pelos alunos na escala numérica. Foram calculadas as frequências de cada nível da escala e porcentagens, as quais foram ilustradas pelos respectivos histogramas. Além disso, excertos das respostas dos alunos foram utilizados para subsidiar as discussões.

\section{Resultados e Discussão}

Na Figura 1 foram apresentados os histogramas obtidos a partir das respostas dos estudantes na escala numérica do instrumento de coleta de dados.

No gráfico da Figura 1(a) é possível verificar que os estudantes avaliaram positivamente a organização do componente curricular: 69,2\% (18 alunos) indicaram o nível 10; 19,2 \% (5 alunos) e 11,5 \% (3 alunos) escolheram os níveis 9 e 8, respectivamente. Em relação à organização, um dos acadêmicos argumentou que as aulas apresentavam uma sequência lógica, além de haver relação com o eixo temático que norteia os componentes no TU e os Projetos Interdisciplinares do TC. Nas palavras do aluno: "Sim. Em uma sequência lógica, sempre relacionando com o eixo temático". Nesse mesmo sentido, outro estudante respondeu que "[...] foi muito bem desenvolvido o componente e feitas as interligaçöes com o nosso dia a dia no âmbito escolar". Assim, destaca-se que o ensino está intimamente relacionado com a organização das aulas, pois, esses aspectos convergem com o empenho de construir uma docência comprometida com a aprendizagem dos alunos. Isso permite potencializar a construção do conhecimento e o desenvolvimento de competências importantes para a formação dos alunos. Nesta perspectiva, Bordenave e Pereira (2010, p. 42, grifos do autor) sugerem que:

[...] o processo de ensino é um processo pragmático, isto é, um mecanismo pelo qual se pretende alcançar certos objetivos e para isso se mobilizam meios, organizando-se em uma estratégia sequencial e combinatória. Mais especificamente, o processo de ensino consistiria em planejar, orientar e controlar a aprendizagem do aluno. 
Cicuto, C. A. T.; Miranda, A. C. G.; Chagas, S. S.
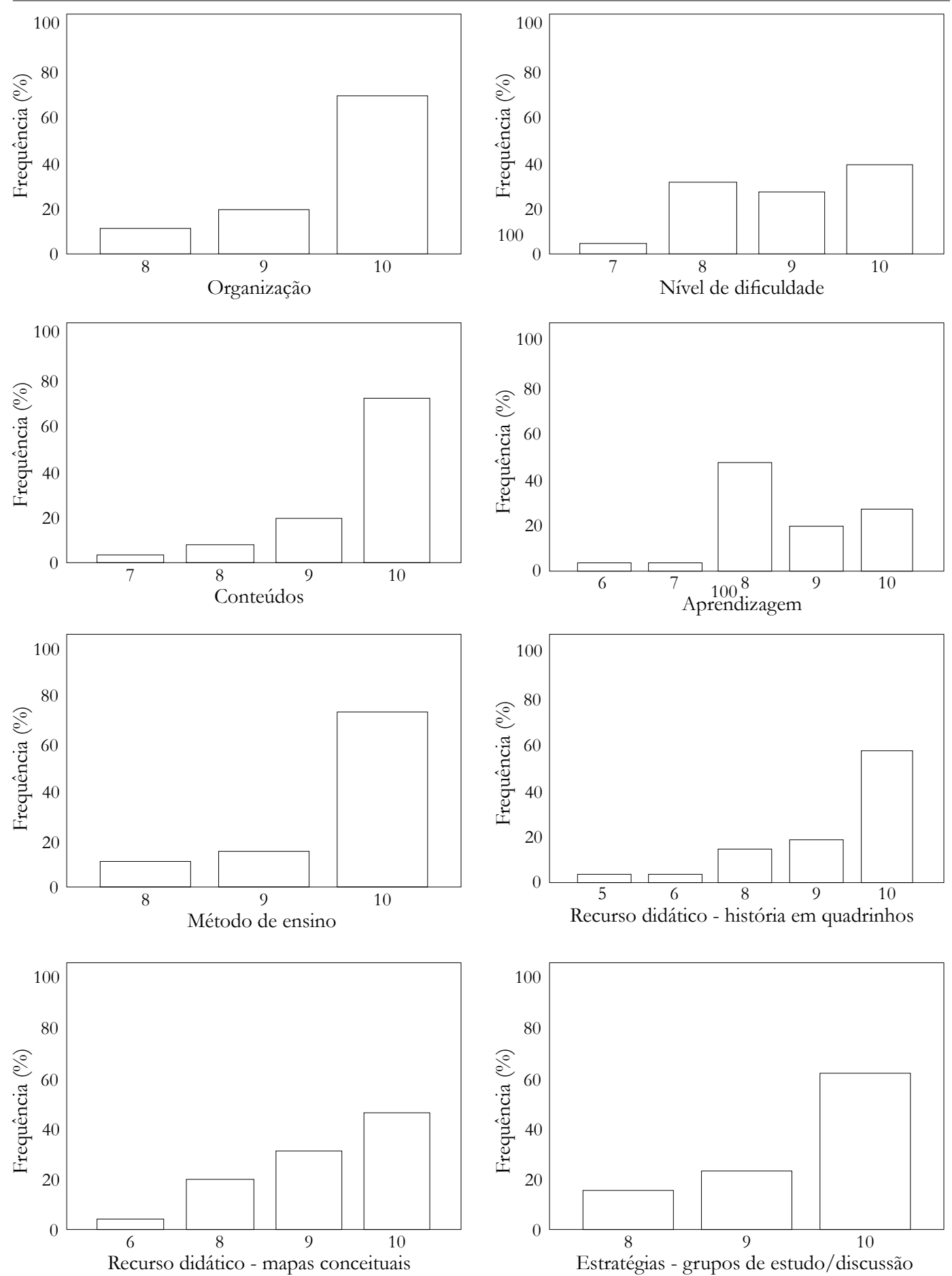

Figura 1 - Histogramas obtidos a partir das respostas dos estudantes na escala numérica Fonte: elaborados pelos autores. 
Na Figura 1(b) é possível verificar a frequência de respostas dos alunos em relação ao nível de dificuldade do componente: 38,5\% (10 alunos) indicaram o nível 10; 26,9\% o nível 9 (7 alunos); 30,8\% o nível 8 (8 alunos) e apenas 3,8\% o nível 7 (1 aluno). Em relação a esse item, um dos alunos argumentou que "[...] surgiram várias dúvidas, mas que ao final eram compreendidas". Essa fala é um indicativo de que, a partir das estratégias de PE e GD, as dúvidas eram esclarecidas por meio da colaboração com os pares e a mediação do professor tornando o nível de dificuldade adequado. As palavras de outro aluno confirmam a adequação do nível de dificuldade: "Sim, achei muito adequado".

No gráfico da Figura 1(c) é possível observar indícios de que os conteúdos abordados no componente de Química foram estimulantes. Neste item, 69,2 \% (18 alunos), 19,2 \% (5 alunos), 7,7\% (2 alunos) e 3,8\% (1 aluno) atribuíram níveis 10, 9, 8 e 7, respectivamente. Um dos acadêmicos ressaltou que: "As aulas são dinâmicas, reflexivas, participativas o que auxilia na compreensão dos conteúdos". Essa resposta evidencia a importância das estratégias utilizadas no componente de Química investigado neste artigo, para promover a interação entre os acadêmicos. No ensino centrado no aluno, o planejamento dos conteúdos tem como critério básico o contexto no qual os indivíduos estão inseridos, tornando-o relevante para eles. No entanto, no ensino tradicional, muitas vezes, a escolha de conteúdo é baseada no índice de livros didáticos. Além disso, os conteúdos são abordados de maneira isolada e baseados na divisão clássica da Química, como Geral, Físico-Química, Orgânica e Analítica (SANTOS; SCHNETZLER, 1996). Assim, é fundamental que os professores universitários proporcionem experiências que qualifiquem seus estudantes, com vistas à formação de um sujeito reflexivo. É preciso romper com o pensamento cartesiano e positivista no Ensino Superior que enfatiza a neutralidade dos conteúdos, criando um ambiente e ações na busca de práticas pedagógicas cujo objetivo seja tornar o aluno o personagem central do processo de aprendizagem. Ainda sobre os conteúdos, outro acadêmico argumentou que: "A metodologia de trabalho da professora me estimula, como futura professora, à metodologia de sempre buscar coisas novas e relacionadas ao cotidiano". Assim, Althaus (2004) aponta que as metodologias diferenciadas vivenciadas no ensino superior podem contribuir efetivamente para a formação de um aluno que não seja simplesmente um mero executor capacitado para uma função, mas que seja um pensador crítico, criativo e solucionador de problemas, tão exigidos hoje no mundo globalizado.

Quando questionados se aprenderam os conceitos científicos do componente de Química (Figura 1(d)) observa-se que 26,9\%, 19,2 \% e 46,2 \% dos alunos atribuíram níveis 10, 9 e 8, respectivamente. Em relação a esse item, um aluno argumentou: "Penso que sim. $O$ suficiente para que eu consiga continuar os estudos no Tempo Comunidade". Outro estudante respondeu: "Não foi difícil, mas temos que prestar muita atenção [...] sem ficarem dúvidas de uma aula para outra". Dessa forma, verificam-se indícios de que a prática pedagógica desenvolvida no ambiente em questão favoreceu a aprendizagem dos conceitos abordados. Sobre esse aspecto, a literatura indica que os alunos aprendem mais em ambiente de aprendizagem centrados no aluno, como resultado do envolvimento deles no processo de ensino-aprendizagem (KNIGHT; WOOD, 2005; SMITH et al., 2009).

Outro ponto investigado se refere à eficiência do método utilizado no componente. Em relação a isso, na Figura 1(e) 71,2\% dos acadêmicos atribuíram o nível 10; 15,4\% e 11,5\% indicaram 9 e 8 , respectivamente. O mesmo padrão foi observado para cada um dos recursos didáticos e estratégias utilizadas (Figuras 1(f) e 1(h)). Em relação a esses itens, os alunos argumentaram que: 
O método foi eficiente, pois foi uma forma diferente de abordar e aprender os conteúdos. Sim, bem diversificado. O que não tornou as aulas cansativas.

[...] Os mapas conceituais fazem com que a turma pense nas inter-relações entre o conteúdo desenvolvido, assim com os grupos de estudo e as histórias em quadrinhos.

A História em Quadrinhos foi uma forma divertida de aprendizado. Os mapas conceituais são um pouco complicados, mas facilitam uma sistematização e o grupo de estudo fez com que trocássemos ideias de maneira mais informal.

Como sugerido anteriormente, pesquisadores da área (ATAÍDE; LIMA; ALVES, 2006; BEHRENS, 2011; COHEN; ROBINSON, 2018; ESTEVES, 2008; KEMBER, 2009) afirmam que muitos educadores, principalmente do nível superior, continuam presos ao pensamento neutro, linear, cartesiano e positivista, acreditando que necessitam depositar conhecimento em seus alunos, enfatizando a memorização, a fragmentação e a simples reprodução dos conteúdos. Esses aspectos vão ao encontro dos estudos sobre a evasão no curso de Física desenvolvido por Ataíde, Lima e Alves (2006). Os autores verificaram que um dos fatores para o abandono do curso são as ações metodológicas e pedagógicas desenvolvidas pelos professores. Assim, os aspectos supracitados corroboram com a relevância das atividades desenvolvidas no componente de Química, investigado na presente pesquisa, uma vez que o componente foi desenvolvido com vistas a formar professores preparados para uma prática em pedagogia que permita romper com o ensino baseado na transmissão-recepção.

Diante disso, não se pode mais idealizar um ensino de química nas universidades que simplesmente apresenta questionamentos pré-concebidos e respostas acabadas. É preciso que o conhecimento químico seja apresentado ao aluno de forma que o possibilite interagir ativa e profundamente com o seu ambiente, entendendo que este faz parte de um mundo do qual ele também é ator e corresponsável.

\section{Considerações finais}

O presente artigo corrobora com as pesquisas sobre práticas pedagógicas que oportunizem um Ensino Superior de qualidade por meio do estudo de alternativas para alterar a dinâmica da sala de aula tradicional. Os resultados apresentados neste artigo indicam que os alunos avaliaram positivamente o ambiente de aprendizagem proporcionado no componente de Química. Essa avaliação é de grande relevância, pois evidencia o potencial das estratégias PE e GD, mapas conceituais e HQs como recursos didáticos para promover o ensino centrado nos alunos. Além disso, ratifica a necessidade da efetivação e divulgação práticas que possibilitem a participação ativa e autônoma dos acadêmicos no processo de ensino-aprendizagem. Contudo, oportunizar um ambiente com tais características exige planejamento, ou ele pode resultar em frustrações para o professor. O planejamento deve considerar que os estudantes trabalhem em grupos para resolver os desafios propostos a eles através de estímulos ao pensamento crítico e criativo. Por fim, deve-se ressaltar que o ambiente de aprendizagem proporcionado neste texto pode ser facilmente utilizado nos diferentes níveis de ensino. 


\section{Referências}

ALLEN, D. E.; DONHAM, R. S.; BERNHARDT, S. A. Problem-based learning. New Directions for Teaching and Learning, Hoboken, v. 2011, n. 128, p. 21-29, 2011. (Special issue). DOI: https://doi.org/10.1002/tl.465.

ALTHAUS, M. T. M. Ação didática no ensino superior: a docência em discussão. Teoria e Prática da Educação, Maringá, v. 7, n. 1, p.101-106, 2004.

ATAÍDE, J. S. P.; LIMA, L. M.; ALVES, E. O. A repetência e o abandono escolar no curso de licenciatura em física: um estudo de caso. Physicae, Campinas, v. 6, n. 6, p. 21- 32, 2006. DOI: https://doi.org/10.5196/physicae.6.5.

ÁVILA JR., P.; TORRES, B. B. Introducing undergraduate students to science.

Biochemistry and Molecular Biology Education, Hoboken, v. 38, n. 2, p. 70-78, 2010. DOI: https://doi.org/10.1002/bmb.20335.

BEHRENS, M. A. Docência universitária: formação ou improvisação? Educação, Santa Maria, v. 36, n. 3, p. 441-454, 2011. DOI: https://doi.org/10.5902/198464442976.

BORDENAVE, J. D.; PEREIRA, A. M. Estratégias de ensino-aprendizagem. 30. ed. Petrópolis: Vozes, 2010.

CICUTO, C. A. T.; TORRES, B. B. Implementing an active learning environment to influence students' motivation in biochemistry. Journal of Chemical Education, Washington, v. 93, n. 6, p. 1020-1026, 2016. DOI: https://doi.org/10.1021/acs. jchemed.5b00965.

CICUTO, C. A. T.; TORRES, B. B. Uma abordagem centrada no aluno em bioquímica: estudo sobre a avaliação da qualidade do ensino. Enseñanza de las Ciencias, Barcelona, n. ext., p. 5529-5534, 2017a.

CICUTO, C. A. T.; TORRES, B. B. Ambiente de aprendizagem centrado no aluno: um estudo sobre expectativas. Enseñanza de las Ciencias, Barcelona, n. ext., p. 5535-5542, 2017b.

COHEN, J.; ROBINSON, C. Enhancing teaching excellence through team-based learning. Innovations in Education and Teaching International, Abingdon, v. 55, n. 2, p. 133-142, 2018. DOI: https://doi.org/10.1080/14703297.2017.1389290.

ESTEVES, M. Para a excelência pedagógica do ensino superior. Sísifo: revista de ciências da educação, Lisboa, n. 7, p. 101-109, 2008.

GRIFFITHS, S. Teaching and learning in small groups. In: FRY, H.; KETTERIDGE, S.; MARSHALL, S. (org.). A handbook for teaching and learning in higher education. $2 \mathrm{nd}$. ed. London: Kogan Page, 2003. p. 91-104. 
Cicuto, C. A. T.; Miranda, A. C. G.; Chagas, S. S.

HARKEMA, S. J. M; SCHOUT, H. Incorporating student-centred learning in innovation and entrepreneurship education. European Journal of Education, Chichester, v. 43, n. 4, p. 513-526, 2008. DOI: https://doi.org/10.1111/j.1465-3435.2008.00372.x.

JOHNSON, R. B.; ONWUEGBUZIE, A. J. Mixed methods research: a research paradigm whose time has come. Educational Researcher, Thousand Oaks, v. 33, n. 7, p. 14-26, 2004. DOI: https://doi.org/10.3102/0013189X033007014.

KEMBER, D. Promoting student-centred forms of learning across an entire university. Higher Education, Dordrecht, v. 58, n. 1, p. 1-13, 2009. DOI: https://doi.org/10.1007/ s10734-008-9177-6.

KNIGHT, J. K.; WOOD, W. B. Teaching more by lecturing less. Cell Biology Education, Bethesda, v. 4, n. 4, p.298-310, 2005.

McMAHON, K. K. Team-based learning. In: JEFFRIES, W. B.; HUGGETT, K. N. (org.). An introduction to medical teaching. Dordrecht: Springer, 2010. p. 55-64.

MAZUR, E. Peer instruction: a user's manual. American Journal of Physics, Melville, v. 67, n. 4, p. 359, 1999. DOI: https://doi.org/10.1119/1.19265.

MICHAELSEN, L. K.; SWEET, M. Team-based learning. New Directions for Teaching and Learning, Hoboken, v. 2011, n. 128, p. 41-51, 2011. (Special issue). DOI: https://doi. org/10.1002/tl.467.

MONTENEGRO, V. L. S.; FERNANDEZ, C. Processo reflexivo e desenvolvimento do conhecimento pedagógico do conteúdo numa intervenção formativa com professores de química. Ensaio: pesquisa em educação em ciências, Belo Horizonte, v. 17, n. 1, p. 251-275, 2015. DOI: https://doi.org/10.1590/1983-211720175170112.

MOREIRA, M. A. Abandono da narrativa: ensino centrado no aluno e aprender a aprender criticamente. Ensino, Saúde e Ambiente, Niteroi, v. 4, n.1, p. 2-17, 2011. DOI: https://doi. org/10.22409/resa2011.v4i1.a21094.

MOREIRA, M. A. Grandes desafios para o ensino da física na educação contemporânea. Revista do Professor de Física, Brasília, v. 1, n. 1, p. 1-13, 2017. DOI: https://doi. org/10.26512/rpf.v1i1.7074.

ROLLNICK, M.; BENNETT', J.; RHEMTULA, M.; DHARSEY, N.; NDLOVU, T. The place of subject matter knowledge in pedagogical content knowledge: a case study of South African teachers teaching the amount of substance and chemical equilibrium. International Journal of Science Education, Abingdon, v. 30, n. 10, p. 1365-1387, 2008. DOI: https:// doi.org/10.1080/09500690802187025. 
SANTOS, W. L. R.; SCHNETZLER, R. P. Função social: o que significa ensino de química para formar o cidadão? Química Nova na Escola, São Paulo, n. 4, p. 28-34, 1996.

SMITH, M. K.; WOOD, W. B.; ADAMS, W. K.; WIEMAN, C.; KNIGHT, J. K.; GUILD, N.; SU, T. T. Why peer discussion improves student performance on in-class concept questions. Science, Washington, v. 323, n. 5910, p. 122-124, 2009. DOI: https://doi.org/10.1126/ science.1165919. 
